Article

\title{
Combustion Studies of a Non-Road Diesel Engine with Several Alternative Liquid Fuels
}

\author{
Michaela Hissa *(1), Seppo Niemi, Katriina Sirviö, Antti Niemi and Teemu Ovaska \\ School of Technology and Innovations, University of Vaasa, P.O. Box 700, FI-65101 Vaasa, Finland; \\ Seppo.Niemi@univaasa.fi (S.N.); Katriina.Sirvio@univaasa.fi (K.S.); Antti.Niemi@univaasa.fi (A.N.); \\ Teemu.Ovaska@univaasa.fi (T.O.) \\ * Correspondence: Michaela.Hissa@univaasa.fi
}

Received: 20 May 2019; Accepted: 23 June 2019; Published: 25 June 2019

\begin{abstract}
Sustainable liquid fuels will be needed for decades to fulfil the world's growing energy demands. Combustion systems must be able to operate with a variety of renewable and sustainable fuels. This study focused on how the use of various alternative fuels affects combustion, especially in-cylinder combustion. The study investigated light fuel oil (LFO) and six alternative liquid fuels in a high-speed, compression-ignition (CI) engine to understand their combustion properties. The fuels were LFO (baseline), marine gas oil (MGO), kerosene, rapeseed methyl ester (RME), renewable diesel (HVO), renewable wood-based naphtha and its blend with LFO. The heat release rate (HRR), mass fraction burned (MFB) and combustion duration (CD) were determined at an intermediate speed at three loads. The combustion parameters seemed to be very similar with all studied fuels. The HRR curve was slightly delayed with RME at the highest load. The combustion duration of neat naphtha decreased compared to LFO as the engine load was reduced. The MFB values of 50\% and $90 \%$ occurred earlier with neat renewable naphtha than with other fuels. It was concluded that with the exception of renewable naphtha, all investigated alternative fuels can be used in the non-road engine without modifications.
\end{abstract}

Keywords: CI engines; alternative fuels; in-cylinder combustion; heat release rate; combustion duration

\section{Introduction}

Limiting global warming requires rapid, far-reaching actions in land, energy, industry, buildings, transport and cities [1]. There is already strong growth of alternative energy sources. However, sustainable liquid fuels will be needed for decades to satisfy the world's growing energy demands [2]. Furthermore, internal combustion engines are set to continue as prime energy producers because there is an established worldwide infrastructure for liquid fuel distribution [3] and the engines offer fuel efficiency, strength and durability [4]. Combustion systems need to be able to operate with a variety of renewable and sustainable fuels and yet also meet increasingly stringent emission legislation. Expanding fuel choice calls for a clearer focus diversification, quality, and usability of any new fuel [5]. Alternative fuels can reduce diesel engine emissions and several beneficial results have already been obtained in practice [6]. However, availability of alternative fuels must evolve to ensure energy security and sustainability. Moreover, their higher price presents a challenge when making new fuel choices [6]. According to Sirviö [6], an alternative fuel must fulfil quality assurance and standard requirements to secure consumer acceptance. In addition, after-treatment applications support a conventional and alternative target for fuels to reduce exhaust emissions.

The distinguishing features of diesel combustion are spontaneous ignition (resulting from the high air temperature and pressure in the cylinder when injection commences) and the fact that fuel-air 
mixing controls the burning rate [7]. Diesel exhaust emissions depend greatly on fuel and lubricating oil properties, engine parameters and exhaust after-treatment technology. Driving and environmental conditions also influence emissions [8]. Cylinder gases' temperature, pressure, density and composition as well as injection timing and injector type, have a direct effect on combustion and emission formation for a given fuel [9]. In-cylinder pressure has a fundamental role in combustion characteristic analyses and it is needed to control combustion-related parameters. Primarily, the peak cylinder pressure depends on the burned fuel fraction during the premixed combustion phase. A large amount of fuel burned in premixed combustion corresponds to a high peak cylinder pressure. [10]

The delay period between the start of injection and start of combustion must be kept short, because injection timing is used to control combustion timing. A short delay is also needed to hold the maximum cylinder gas pressure below the maximum the engine can tolerate. [7] Therefore, the main ignition characteristic of a diesel fuel-its cetane number $(\mathrm{CN})$ must be above a certain value.

This study focused on how the use of various alternative fuels affects combustion, especially in-cylinder combustion. A baseline fuel and six alternative liquid fuels were investigated in a high-speed compression-ignition (CI) engine to understand their combustion properties. The fuels were light fuel oil (LFO, baseline), marine gas oil (MGO), kerosene, rapeseed methyl ester (RME), renewable diesel (HVO), renewable wood-based naphtha and its blend with LFO.

One potential substitute for conventional fuels is mineral origin alternative oils, such as recycled waste oils. Recycling waste lubricant oils (WLO) into diesel-like fuels is an environmentally friendly solution because waste oils are classified as a hazardous waste [11,12]. In this study, the first alternative was marine gas oil (MGO), produced from waste lubricating oils. MGO is commonly known as a shipping fuel, and currently it is largely used when a vessel is inside an emission control area (ECA) or within EU ports. Sulphur emission regulations are becoming increasingly stringent and, in the case of older ships, the use of MGO is suggested to be more beneficial than retrofitting scrubbers [13]. Recently, Wang and Ni [14] and Gabiña et al. [4] have also investigated diesel-like fuel (DLF) manufactured from WLO.

Kerosene is primarily used in the aviation sector. However, the U.S. Army and the North Atlantic Treaty Organization (NATO) have a single military fuel policy-mandating the use of kerosene-based jet fuels in ground vehicles equipped with CI engines, thereby simplifying supply chain logistics [15]. Kerosene has been studied for its pollutants reduction potential. Amara et al. [16] presents studies where kerosene's higher volatility lowered $\mathrm{NO}_{\mathrm{X}}$ emissions compared to diesel in a $\mathrm{CI}$ engine. Hissa et al. [17] also investigated neat kerosene in a combustion research unit (CRU) and concluded that other fuel may be needed for starting and stopping the engine, or different injection nozzles used. Kerosene's low lubricity may also cause a malfunction in the injection system. Nevertheless, kerosene was considered an interesting alternative for future special CI engine applications.

First generation biodiesels, known as FAME or fatty acid methyl esters, have been studied for a long time. Despite some problems, they still arouse great interest [6]. In Europe, the maximum FAME content in conventional diesel fuel is $7 \mathrm{~V}-\%$ according to EN590:2013. However, in the United States, the renewable share is in some cases above $20 \mathrm{~V}-\%$, and even their own standard EN 16709 for B20 and B30 fuels. [6] Biodiesel fuels' different types of properties have a strong relation with their fatty acid composition. Poor cold properties and poor storage stability are the main problems associated with the use of FAME fuels [6]. The review article of Shahabuddin et al. [18] reported that the combustion characteristics of a bio-fuelled engine are slightly different from the engine running with petroleum diesel. This was one of the main reasons also to include rapeseed methyl ester (RME) in the present study.

Hydrotreated vegetable oils (HVO) are one of the easiest ways to increase the bio-component in diesel fuel. Moreover, they are highly recommended by vehicle and engine manufacturers [19]. The production process of hydrotreated fuels differs from FAME and this neat renewable diesel can be used in diesel engines without blending. HVO is sulphur and aromatic-free fuel which can be produced from various wastes such as animal fats, residues of forest industry and wastes from the food industry. 
HVO offers some advantages compared to FAME (e.g., RME), including a higher cetane number (CN), better storage stability and fewer problems with cold operability and deposits [8]. HVO's properties correspond to those of traditional fossil fuels but a significant reduction of up to $80 \%$ in greenhouse gaseous emissions is achieved [5]. Furthermore, crude tall oil-based (CTO) fuels do not compete with the food chain and there is no direct land-use change [5]. A Finnish forestry company manufactured the CTO renewable diesel used in the study.

Renewable, wood-based naphtha is another interesting and novel fuel. This study's naphtha was made from CTO extracted in the pulp production process. This colourless, sulphur-free, paraffinic product is chemically pure hydrocarbon and can be used as a bio-component in fossil gasoline [20]. Conventionally, naphtha is produced from crude oil and is suitable for use in compression-ignition (CI) engines $[14,21,22]$. However, raw naphtha has a low cetane number $(\mathrm{CN})$ which may cause prolonged ignition delay (ID) and hence may retard the start of combustion [23]. Hissa et al. [17] observed that ignition of neat wood-based naphtha had a retarded start of combustion and prolonged ID when measured in a CRU. This may limit use of neat naphtha as fuel in diesel engines. Neat naphtha also needs other fuel (e.g., LFO) for starting and stopping the engine. However, there is very little research into wood-based naphtha, prompting the inclusion of this fuel in the current study as an interesting renewable option, especially for blending.

Various liquid fuel options are needed in the near future for flexible power generation, marine and heavy-duty applications. Consequently, this study was carried out to evaluate the effects of alternative fuels' properties in an engine use and to promote the development of fuel processes and standard to meet engine requirements. The focus was on how various properties of the alternative fuels affects combustion, especially in-cylinder combustion. The cylinder pressures, heat release rates (HRR), mass fractions burned (MFB) and combustion duration were determined at an intermediate speed at three loads. The experimental engine was a high-speed common-rail diesel engine intended for non-road applications. All measurements were performed under steady operation conditions without engine modifications. The study continued with the emission analysis in the article by Ovaska et al. [24].

\section{Materials and Methods}

The engine experiments were conducted by the University of Vaasa (UV) at the Internal Combustion Engine (ICE) laboratory of the Technobothnia Research Centre in Vaasa, Finland.

\subsection{Fuels}

The studied fuels were selected with the aim of increasing the choice of fuel alternatives for non-road compression-ignition engines. The baseline fuel was a commercial low-sulphur light fuel oil (LFO) from Teboil, Finland. Jet A-1 aviation fuel (100\% kerosene) was produced by Neste, Finland. Marine gas oil (MGO) produced from waste lubricant oils, was a product of STR Tecoil, Finland. Hydrotreated vegetable oil (HVO), also known as CTO-based renewable diesel, was produced by UPM, Finland. Rapeseed methyl ester (RME) was a product of Analytik-Service Gesellschaft mbH, Germany. Wood-based naphtha was made from CTO, extracted in the pulp production process, and was produced by UPM, Finland. Renewable naphtha was also blended with LFO (20 V-\% naphtha and $80 \mathrm{~V}-\%$ LFO), also known as naphtha20. Chemically, all the fuels contained several hydrocarbon compounds, therefore simple chemical formulas could not be given. Table 1 summarises the specifications of the studied fuels.

Cetane number $(\mathrm{CN})$ is an indicator of the ignition quality of diesel fuel [7]. A high $\mathrm{CN}$ indicates good ignitability in a diesel engine. As shown in Table 1, the $\mathrm{CN}$ of the fuels ranged from 34 (neat naphtha) to 68 (recycled MGO). The CN of kerosene, naphtha20, LFO, RME and HVO were 41, 51, 52, 53 and 65 , respectively.

There is an indirect relationship between density and other fuel parameters such as $\mathrm{CN}$, viscosity, volatility and distillation characteristics [25]. It has also been shown that fuel density can have a direct 
effect on the progress of fuel pressure in the injection system and a consequent effect on the dynamic start of fuel injection [25]. Neat naphtha had the lowest density $\left(722 \mathrm{~kg} \mathrm{~m}^{-3}\right)$, markedly lower than that of the baseline LFO $\left(827 \mathrm{~kg} \mathrm{~m}^{-3}\right)$. Lower density may result in lower engine power and also affects volumetric fuel consumption. The highest density was measured for RME $\left(883 \mathrm{~kg} \mathrm{~m}^{-3}\right)$.

A higher mass-basis lower heating value (LHV) may result in a higher heat input to the engine, i.e., higher cylinder pressures and increased power output. The LHV of most of the studied fuels was 43-44 MJ kg-1. The one exception was RME, with a LHV of 37 to $38 \mathrm{MJ} \mathrm{kg}^{-1}$.

Legislation has driven down fuel's sulphur content. A lower, new sulphur limit $\left(5,000 \mathrm{mg} \mathrm{kg}^{-1}\right)$ will be implemented in the maritime sector on 1 January 2020 [26]. In Finland, non-road diesel engine fuels must comply with EN 590:2013 standard, setting a maximum limit for sulphur content of $10 \mathrm{mg} \mathrm{kg}^{-1}$ [27]. Regarding the studied fuels, kerosene (1000 $\left.\mathrm{mg} \mathrm{kg}^{-1}\right)$ and MGO $\left(<100 \mathrm{mg} \mathrm{kg}^{-1}\right)$ had sulphur exceeding EN 590:2013's limit.

Diesel fuel injection systems are lubricated mainly by the fuel itself. However, when sulphur level of a fuel is reduced, the process also destroys some of the fuel's natural lubricants [28]. To avoid wear in the fuel injection system, a minor portion of lubrication additive (1:4000) was added to kerosene to avoid possible malfunctions in engine use. This amount of lubrication additive should not have any effect on the autoignition properties of the fuel. Also, MGO had lower lubricity than LFO. This might be shown as injection system failures over the time. In addition, longer engine measurements are required to examine the effect of the lubricity.

Table 1. Fuel specifications.

\begin{tabular}{ccccccccc}
\hline Parameter & Unit & LFO & MGO & Naphtha & Kerosene & RME & HVO & Naphtha20 \\
\hline Flash point & ${ }^{\circ} \mathrm{C}$ & 63 & 110 & 20 & 38 & 179 & $78^{\mathrm{b}}$ & \\
Density at $15^{\circ} \mathrm{C}$ & $\mathrm{kg} \mathrm{m}^{-3}$ & 827 & 843 & 722 & 787 & 883 & 813 & 805 \\
Kin. viscosity $\left(40^{\circ} \mathrm{C}\right)$ & $\mathrm{mm}^{-1}$ & 1.84 & 7.69 & 0.50 & 0.94 & 4.49 & 3.5 & 1.37 \\
LHV & $\mathrm{MJ} \mathrm{kg}^{-1}$ & 43 & 43 & 44 & 43 & $37-38^{\mathrm{b}}$ & & \\
Cetane number & - & 52 & 68 & 34 & 41 & 53 & 65 & 51 \\
Sulphur content & $\mathrm{mg} \mathrm{kg}^{-1}$ & 8.3 & $<100$ & & 1000 & $<5$ & $<1^{\mathrm{b}}$ & 6.8 \\
Ash content $\left(775^{\circ} \mathrm{C}\right)$ & $\mathrm{wt}^{\circ} \%$ & $<0.001$ & $<0.001$ & 0.005 & 0.001 & & $<0.005^{\mathrm{c}}$ & \\
Water content & $\mathrm{mg} \mathrm{kg}^{-1}$ & 61 & 22 & & 35 & $<30$ & $<30^{\mathrm{c}}$ & \\
Lubricity & $\mu \mathrm{m}$ & 345 & 491 & & $4477^{\mathrm{a}}$ & \multicolumn{3}{c}{$228^{\mathrm{c}}$} \\
\hline a
\end{tabular}

${ }^{a}$ Value includes added lubricity improver, ${ }^{b}$ Hassaneen et al. [29], Tira et al. [30], ${ }^{c}$ Niemi et al. [5]

Safety issues are also critical when introducing new fuels. Fuel suppliers have to specify the fuel properties and confirm compliance with industry standards. These properties include flashpoint, combustibility, stability, compatibility, viscosity, lubricity, etc. Every one of these properties, if not properly addressed, can affect equipment performance and/or reliability and above all, affect safety of personnel or the engine's safe operation [31]. In the present study, the low flash points of neat naphtha $\left(20^{\circ} \mathrm{C}\right.$ ) and kerosene $\left(38^{\circ} \mathrm{C}\right.$ ), and their low viscosity (naphtha $0.50 \mathrm{~mm}^{2} \mathrm{~s}^{-1}$ and kerosene $0.94 \mathrm{~mm}^{2} \mathrm{~s}^{-1}$ ) necessitated additional safety procedures when handling the fuels and making measurements in the engine. For the studied fuels, the compatibility of the engine, fuel system and auxiliaries was ensured. Additionally, the engine operators used respirator masks and gloves during the measurements.

\subsection{Engine}

The test engine, an AGCO Power 44 AWI, was a high-speed four-cylinder diesel engine for non-road applications. It was turbocharged, intercooled and had Bosch common-rail fuel-injection. It was loaded by means of a Horiba eddy-current dynamometer WT300. The engine's specification is in Table 2. 
Table 2. Test engine specification.

\begin{tabular}{cc}
\hline Engine & AGCO POWER 44 AWI \\
\hline Cylinder number & 4 \\
Bore $(\mathrm{mm})$ & 108 \\
Stroke $(\mathrm{mm})$ & 120 \\
Swept volume $\left(\mathrm{dm}^{3}\right)$ & 4.4 \\
Rated speed $\left(\mathrm{min}^{-1}\right)$ & 2200 \\
Rated power $(\mathrm{kW})$ & 101 \\
Maximum torque at $15001 \mathrm{~min}^{-1}(\mathrm{Nm})$ & 585 \\
\hline
\end{tabular}

\subsection{Analytical Instruments}

LabVIEW system-design software was used to collect the sensor data from the engine. The recorded variables were engine speed and torque, cylinder pressure and injection timing, duration and quantity. A WinEEM4 program provided by the engine manufacturer, AGCO Power, controlled fuel injection according to load-speed requests. The basic settings of WinEEM4 were the same for all fuels. A schematic of the setup of the test bench is in Figure 1.

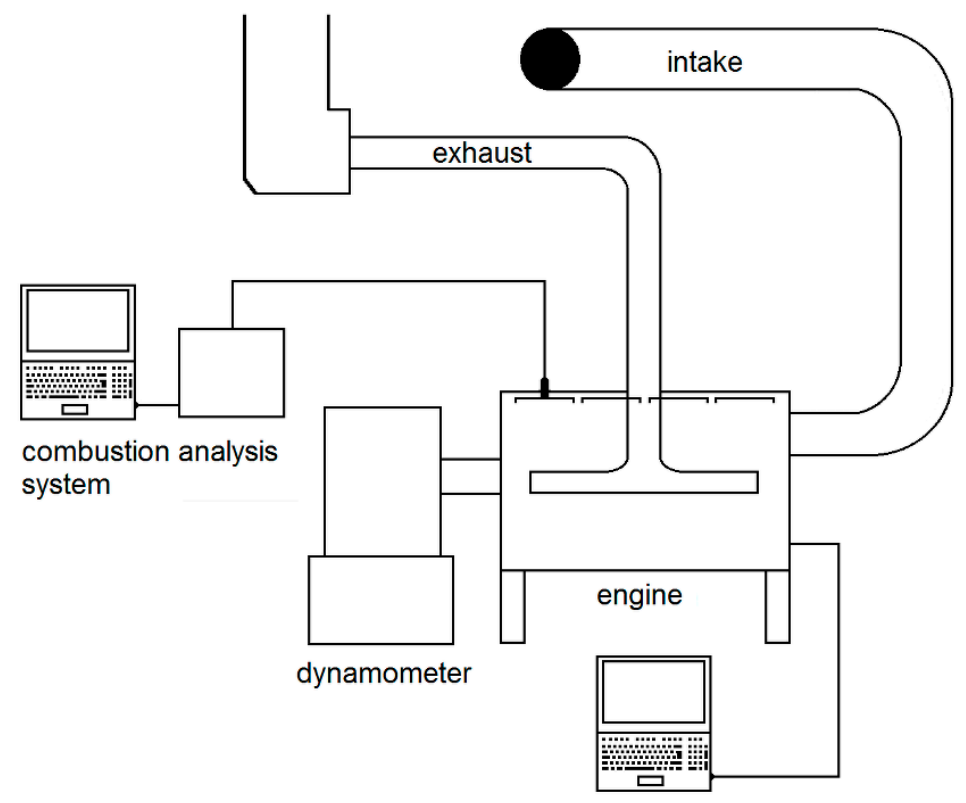

Figure 1. Schematics of the experimental system.

A piezoelectric Kistler 6125C pressure sensor was used to measure in-cylinder pressure. The sensor was mounted on the head of the fourth cylinder. A charge amplifier filtered and amplified the signal, which was then transmitted to a Kistler KIBOX combustion analyser. The crankshaft position was recorded by a crank-angle encoder (Kistler 2614B1), which can output a crank-angle signal with a resolution of $0.1^{\circ} \mathrm{CA}$ by means of an optical sensor. The cylinder-pressure data was averaged over 100 consecutive cycles to smooth irregular combustion. The averaged data was used to calculate HRR.

The HRR and MFB were calculated via AVL Concerto's data-processing platform, using the Thermodynamics 2 macro. The macro used a calculation resolution of $0.2{ }^{\circ} \mathrm{CA}$. The start of the calculation was set at $-30^{\circ} \mathrm{CA}$. The data were filtered with the DigitalFilter macro and a frequency of $2500 \mathrm{~Hz}$. For the HRR results, the average values of in-cylinder pressure were calculated first. Thereafter, the macro was used to calculate HRR values. Finally, the HRR curve was filtered. In contrast, for the MFB results, pressure values were first filtered and then the macro was used. The average values of 100 cycles were not used for MFB results, establishing the standard deviations. 


\subsection{Experimental Matrix and Measurement Procedure}

All measurements were performed under steady operation conditions without engine modifications. The measurements were conducted based on ISO 8178-4 standard, known as non-road steady cycle (NRSC). Additionally, the $25 \%$ (3.2 bar) load point was measured at an intermediate speed. With low-viscosity kerosene and neat naphtha, the default engine control parameters made running the engine possible only at an intermediate speed. The added $25 \%$ load point gave more information during the experiment, because no engine parameter optimization was applied. Multistage injection (pilot, main and post injections) was used throughout the study. The operating conditions chosen were an engine speed of $1500 \mathrm{~min}^{-1}$ and three different loads-Brake-mean effective pressures (BMEP) of 3.2 bar, 6.4 bar and 9.7 bar. The loads are in Table 3 .

Table 3. Engine operating conditions with light fuel oil (LFO).

\begin{tabular}{lccc}
\hline Engine Speed $\left(\mathbf{m i n}^{-1}\right)$ & $\mathbf{1 5 0 0}$ & & \\
\hline BMEP (bar) & 3.2 & 6.4 & 9.7 \\
Load $(\%)$ & 25 & 50 & 75 \\
Torque $(\mathrm{Nm})$ & 113 & 225 & 338 \\
\hline
\end{tabular}

\subsection{Injection Strategy}

Pilot injection shortens the ID of a fuel by increasing in-cylinder temperatures for main injections. Post injections, in turn, are used to reduce particulate and soot emissions, primarily at lighter loads and lower engine speeds [7].

For all the fuels at all loads, the pilot injection was constant. It started at $6.8 \pm 0.1^{\circ} \mathrm{CA}$ BTDC and ended at $4.1^{\circ} \mathrm{CA} \mathrm{BTDC}$. The main injection started at exactly $0.9^{\circ} \mathrm{CA}$ BTDC. The duration of the main injection varied not only with the load, but also according to the fuel's heating value. The main injection was always longest with RME (5.2 to $8.2{ }^{\circ} \mathrm{CA}$ depending on the load), due to its lower LHV. The main injection durations for the other fuels were very similar $\left(4.8-7.7^{\circ} \mathrm{CA}\right.$ according to engine load). The start of post injection was linked to the end of main injection, and was thus delayed according to the fuel's LHV. The duration of post injection varied only slightly in the range of $3.3^{\circ} \mathrm{CA}$ and $3.6^{\circ} \mathrm{CA}$ and was independent of the load. The pilot and main injections are the most important factors when considering ignition delay, that is, HRR and MFB values.

The engine was started with LFO in all fuel tests. Then, fuel was changed to test fuel and the engine was warmed-up and the load was applied. The intake-air temperature was adjusted to $100^{\circ} \mathrm{C}$ downstream of the charge-air cooler to support auto-ignition of the fuels at each load. The temperature was controlled manually by regulating the flow of cooling water to the heat exchanger. The valve setting was kept constant. Therefore, the charge temperature changed with the load. All measurements were taken only after the engine had stabilized, as determined by stability of the temperature of coolant water, intake air and exhaust.

\section{Results and Discussion}

This section presents and discusses the results of the studied fuel's combustion characteristics in terms of engine in-cylinder pressure, the rate of heat release and mass fraction burned. The main results of the emission analysis are provided, based on the article of Ovaska et al. [24].

\subsection{Heat Release Rate (HRR)}

The combustion process includes three stages. In the first stage, the rate of burning is rapid, lasts for only few CA degrees and produces the first spike in the HRR. The second stage is the main heat-release period and it has more rounded profile with longer duration. The third stage, the tail, is the remainder of the fuel's chemical energy released when burned gases mix with excess air that was not involved in the main combustion. [7] Figure 2a-c depicts the cylinder pressure traces and 
Figure $2 \mathrm{~d}-\mathrm{f}$ the HRR curves. A slight loss in HRR curves was observed at the beginning due to the heat transfer into the liquid fuel, vaporizing and heating it [7].

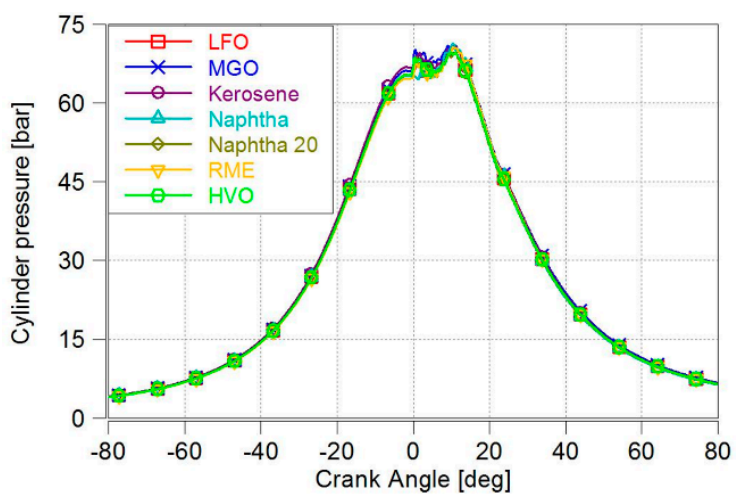

a) $B M E P=3.2$ bar

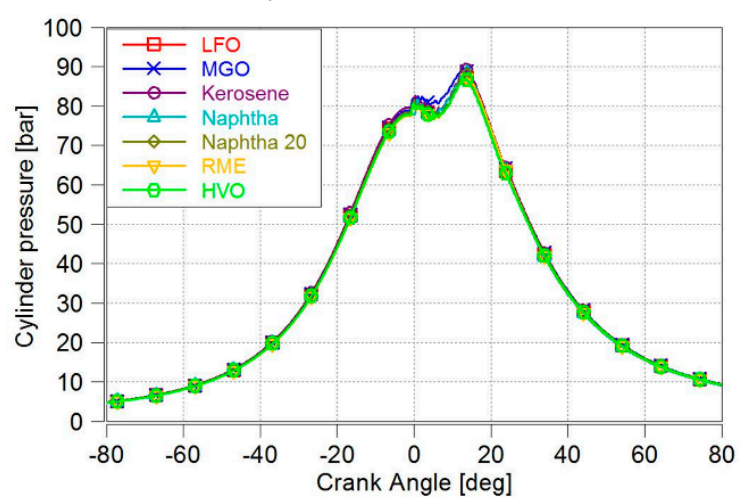

b) $\mathrm{BMEP}=6.4$ bar

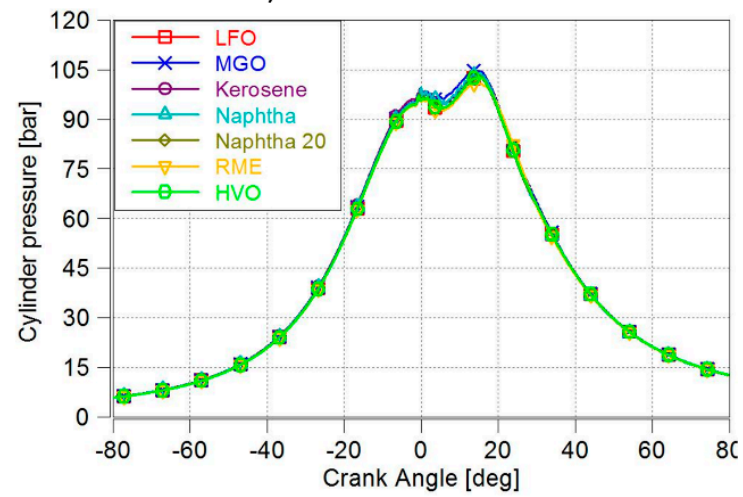

c) BMEP=9.7 bar

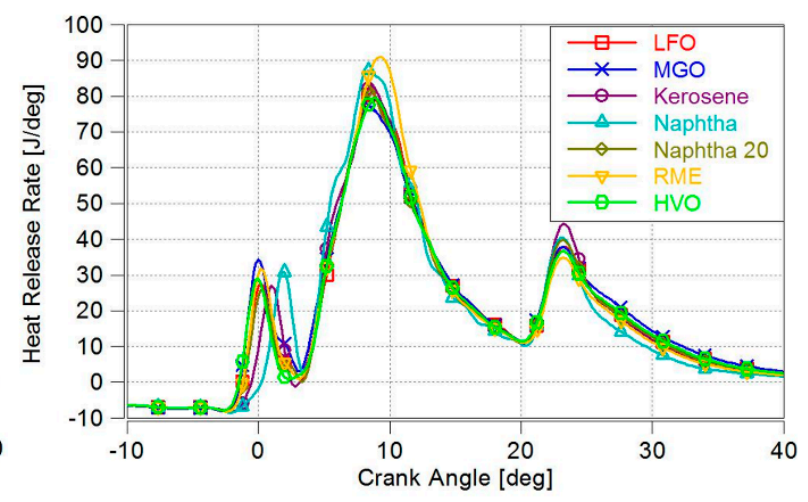

d) $B M E P=3.2$ bar

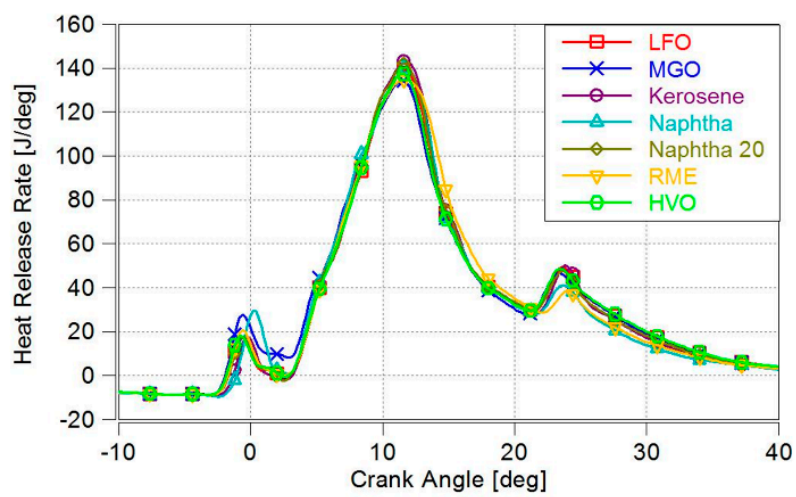

e) $\mathrm{BMEP}=6.4 \mathrm{bar}$

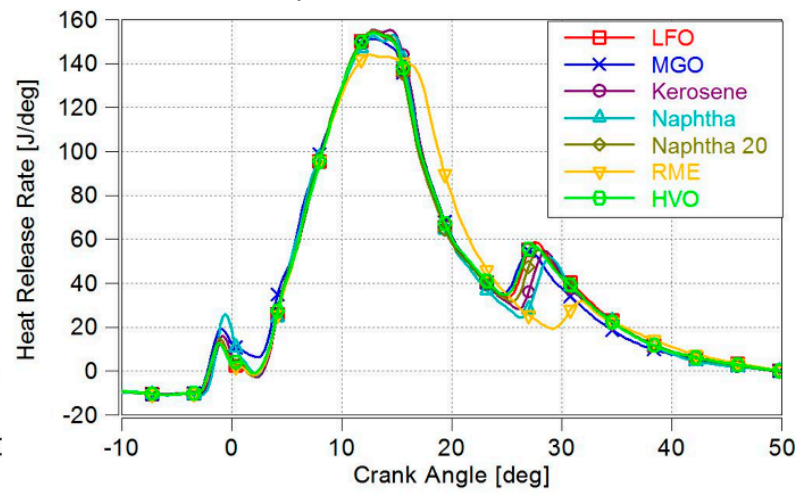

f) $B M E P=9.7$ bar

Figure 2. In-cylinder pressure and heat release rates at different engine loads.

At the lowest load (3.2 bar BMEP), the longer ID of naphtha and kerosene are apparent. Other fuels burned in a quite similar way, although MGO showed a slightly higher initial HRR. The highest maximum HRR peak was recorded with RME, maybe due to its high oxygen content triggering rapid initial combustion. Aldhaidhawi et al. [32] also mentioned that an increase in the fuel's oxygen fraction provided an increase in the premixed combustion stage. More rapid combustion of oxygen-containing bio-fuel has previously been noted, for example by Niemi et al. [33]. After a longer ID due to low $\mathrm{CN}$, naphtha seemed to also burn fast, most probably due to light high-volatile compounds and the favourable effects of the low viscosity on fuel/air mixture formation. The HRR peaks of other fuels were rather similar.

At the medium load (6.4 bar BMEP), no clear differences in the ID were detected. The initial HRR of kerosene was low, but kerosene showed the highest HRR peak. Kerosene's low CN delayed start of 
combustion but rapid burning may be a result of higher volatility of its lighter fractions. (Amara et al. 2016) MGO once again showed the highest initial but the lowest peak for HRR. Naphtha had a high initial HRR, but lower post injection HRRs peak than other fuels, except RME, which also showed low HRR after post-injection.

At high load (9.7 bar BMEP), the highest HRR values were rather similar for all fuels except RME. Its HRR curve was slightly delayed due to its lower LHV and lengthened main injection. Consequently, there was also a delay in RME's post-injection HRR peak. Neat naphtha showed a higher initial HRR than other fuels at high load, and its post-injection HRR peak was moderate, unlike its low peak at medium load.

\subsection{Mass Fraction Burned (MFB)}

At all loads, MGO had the earliest MFB 5\% and 10\% positions due to the high CN and short ID (Table 4). Neat naphtha had the earliest MFB 50\% and MFB 90\% at low and medium loads. Although naphtha's low CN increased the ID, it burned rapidly due to improved premixed combustion [34].

Table 4. Mass fraction burned and combustion durations (MFB 5-50\% and MFB 5-90\%).

\begin{tabular}{|c|c|c|c|c|c|c|c|}
\hline ВMEP & Fuel & MFB 5\% & MFB $10 \%$ & MFB $50 \%$ & MFB 90\% & CD $5-50 \%$ & CD 5-90\% \\
\hline bar & & ${ }^{\circ} \mathrm{CA}$ & ${ }^{\circ} \mathrm{CA}$ & ${ }^{\circ} \mathrm{CA}$ & ${ }^{\circ} \mathrm{CA}$ & ${ }^{\circ} \mathrm{CA}$ & ${ }^{\circ} \mathrm{CA}$ \\
\hline \multirow[t]{7}{*}{3.2} & LFO & 7.5 & 8.1 & 14 & 29 & 6.3 & 22 \\
\hline & MGO & 7.0 & 7.7 & 14 & 30 & 6.8 & 23 \\
\hline & Kerosene & 7.5 & 8.1 & 14 & 28 & 6.2 & 21 \\
\hline & Naphtha & 7.2 & 7.7 & 12 & 27 & 5.2 & 20 \\
\hline & Naphtha20 & 7.5 & 8.1 & 14 & 29 & 6.2 & 21 \\
\hline & RME & 7.3 & 7.9 & 13 & 28 & 5.2 & 21 \\
\hline & HVO & 7.3 & 8.0 & 14 & 29 & 6.4 & 22 \\
\hline \multirow[t]{7}{*}{6.4} & LFO & 8.1 & 8.9 & 14 & 28 & 5.8 & 20 \\
\hline & MGO & 7.2 & 8.1 & 13 & 28 & 6.2 & 21 \\
\hline & Kerosene & 8.0 & 8.8 & 14 & 27 & 5.6 & 19 \\
\hline & Naphtha & 7.7 & 8.5 & 13 & 26 & 5.5 & 19 \\
\hline & Naphtha20 & 8.0 & 8.8 & 14 & 28 & 5.7 & 20 \\
\hline & RME & 7.9 & 8.7 & 14 & 27 & 5.7 & 19 \\
\hline & $\mathrm{HVO}$ & 8.0 & 8.8 & 14 & 28 & 5.9 & 20 \\
\hline \multirow[t]{7}{*}{9.7} & LFO & 8.4 & 9.4 & 16 & 31 & 7.2 & 23 \\
\hline & MGO & 7.7 & 8.9 & 15 & 30 & 7.5 & 22 \\
\hline & Kerosene & 8.4 & 9.4 & 16 & 31 & 7.1 & 22 \\
\hline & Naphtha & 8.1 & 9.2 & 15 & 31 & 7.1 & 23 \\
\hline & Naphtha20 & 8.3 & 9.3 & 15 & 31 & 7.1 & 23 \\
\hline & RME & 8.4 & 9.4 & 16 & 31 & 7.5 & 23 \\
\hline & HVO & 8.3 & 9.4 & 16 & 31 & 7.3 & 23 \\
\hline
\end{tabular}

At low load (3.2 bar BMEP), the latest MFB 5\% was measured for naphtha20 (7.5 ${ }^{\circ} \mathrm{CA}$ ATDC); the latest MFB $10 \%$ was for kerosene ( $8.1^{\circ} \mathrm{CA}$ ATDC). The earliest positions for MFB $5 \%$ and MFB $10 \%$ were observed for MGO (7.0 and $7.6^{\circ} \mathrm{CA}$ ATDC, respectively). However, MFB 50\% and $90 \%$ were latest with MGO (14 and $30^{\circ} \mathrm{CA}$ ATDC). MGO's high CN facilitated the early start of combustion. However, MGO had the highest viscosity $\left(7.69 \mathrm{~mm}^{2} \mathrm{~s}^{-1}\right)$ and this may have led to poorer mixing, giving more inhomogeneity zones than with neat naphtha. Poor mixture formation lead to a longer combustion duration and a lower rate of heat release [30]. The earliest MFB 50\% and $90 \%$ were with neat naphtha (12 and $27^{\circ} \mathrm{CA}$ ATDC), which had a low $\mathrm{CN}$ but higher volatility and considerably lower density than MGO.

At medium load (6.4 bar BMEP), LFO gave the latest MFB 5\%, 10\% and 50\% (8.1, 8.9 and $14{ }^{\circ} \mathrm{CA}$ ATDC, respectively). MFB 90\% was the latest for HVO ( $28^{\circ} \mathrm{CA}$ ATDC). Neat naphtha and MGO showed rapid combustion at the medium load. 
At the high load (9.7 bar BMEP) with higher in-cylinder pressure and temperature, MGO also had the earliest MFB 50\% ( $15^{\circ} \mathrm{CA}$ ATDC, Table 5) and MFB $90 \%$ ( $30^{\circ} \mathrm{CA}$ ATDC). The latest MFB $90 \%$ was measured for RME ( $31^{\circ} \mathrm{CA}$ ATDC). In fact, at this highest load, RME was the latest fuel at all MFB positions. This was also evident in the cylinder pressures: RME was slightly lower than with other fuels. The HRR curve of RME was also delayed compared with other fuels. It was assumed that RME's high oxygen content accelerated combustion at lower loads. At high load, however, RME's lengthened injection period, stemming from its low LHV, outweighed the advantage of high oxygen content. It is possible that higher in-cylinder pressures and temperatures also improved the HRR of other fuels relative to RME.

Table 5. Average values and standard deviations of mass fractions burned (MFB) 50\%.

\begin{tabular}{ccccccc}
\hline \multirow{2}{*}{ Fuels } & \multicolumn{2}{c}{ BMEP 3.2 bar } & \multicolumn{2}{c}{ BMEP 6.4 bar } & \multicolumn{2}{c}{ BMEP 9.7 bar } \\
\cline { 2 - 7 } & MFB 50\% & Stdev & MFB 50\% & Stdev & MFB 50\% & Stdev \\
\hline Unit & ${ }^{\circ}$ CA & ${ }^{\circ}$ CA & ${ }^{\circ}$ CA & ${ }^{\circ}$ CA & ${ }^{\circ}$ CA & ${ }^{\circ}$ CA \\
\hline LFO & 14 & 0.16 & 14 & 0.083 & 16 & 0.095 \\
MGO & 14 & 0.22 & 13 & 0.11 & 15 & 0.11 \\
Kerosene & 14 & 0.19 & 14 & 0.095 & 16 & 0.10 \\
Naphtha & 12 & 0.17 & 13 & 0.081 & 15 & 0.088 \\
Naphtha20 & 14 & 0.19 & 14 & 0.095 & 15 & 0.088 \\
RME & 13 & 0.12 & 14 & 0.091 & 16 & 0.10 \\
HVO & 14 & 0.15 & 14 & 0.084 & 16 & 0.093 \\
\hline
\end{tabular}

\subsection{Combustion Duration}

Combustion duration (CD) can be expressed as the time interval between MFB 5\% and MFB 50\% (Figure 3 and Table 4) and the interval between MFB 5\% and MFB 90\% (Figure 4 and Table 4) which are linearly correlated at constant engine-speeds. For all the fuels at all loads, even MFB $5 \%$ occurred after the end of the main injection (Table 4). MFB 10\% and 50\% were achieved before post injection. MFB $90 \%$ occurred after the end of post injection.

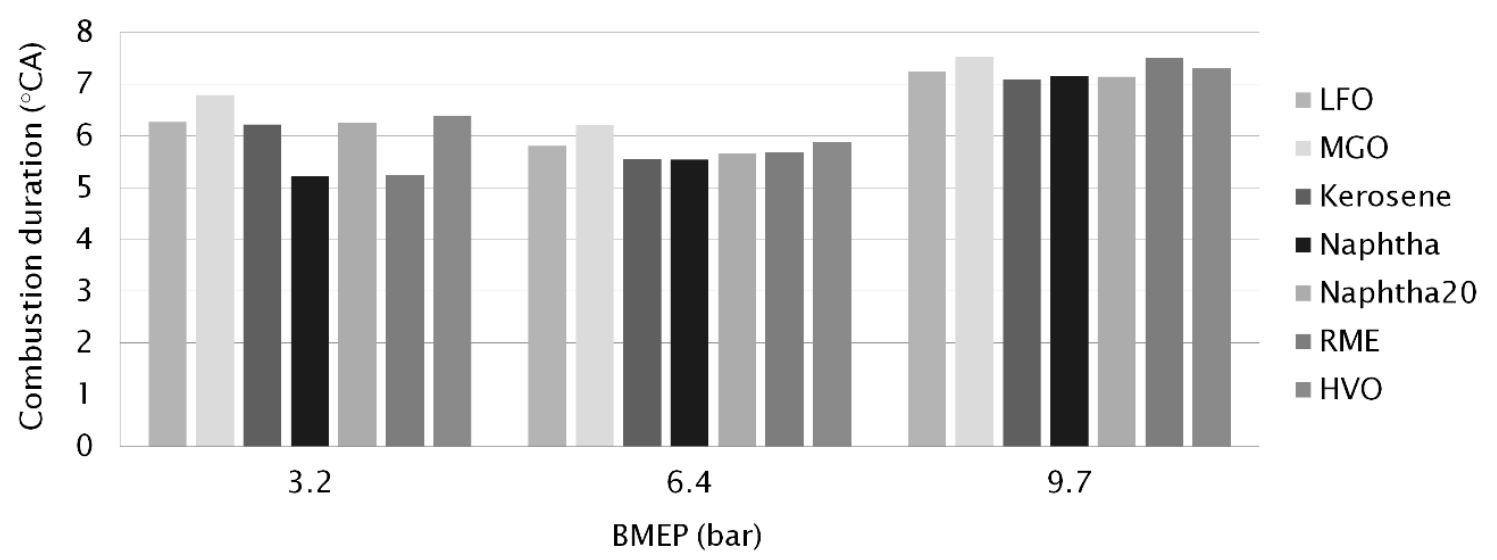

Figure 3. Combustion duration $\left({ }^{\circ} \mathrm{CA}\right)$ at different engine-loads, determined as crank angles between MFB 5\% and MFB 50\%. 


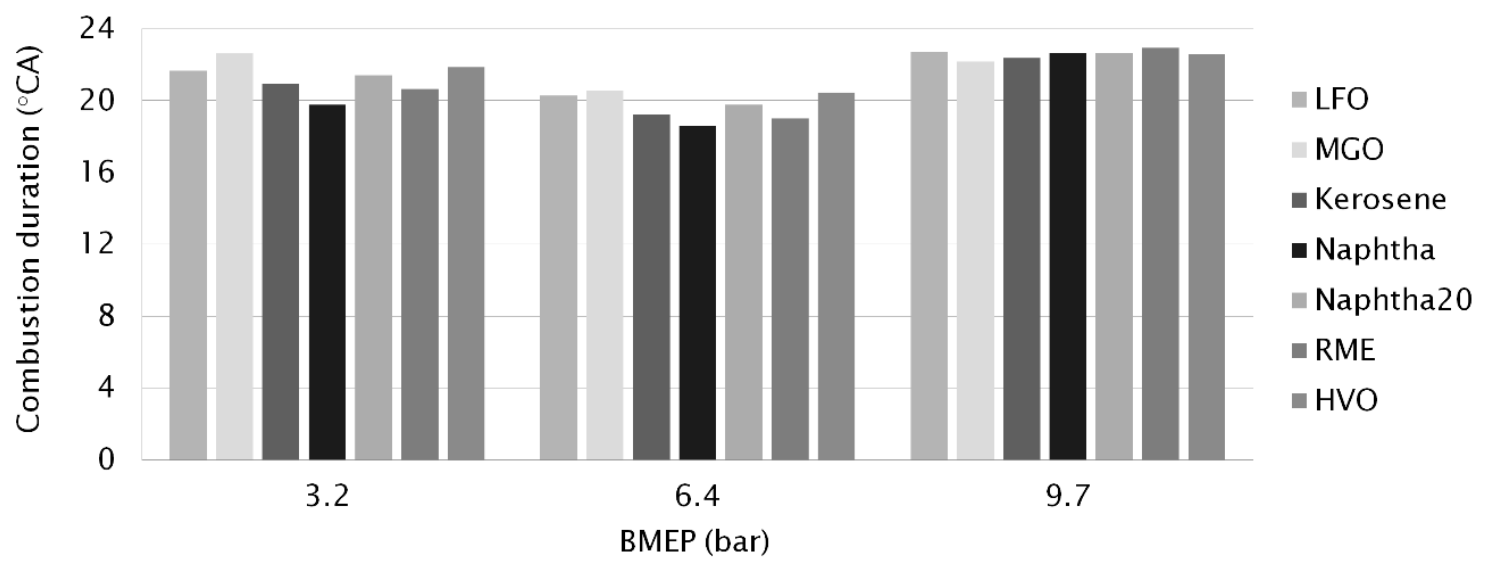

Figure 4. Combustion duration $\left({ }^{\circ} \mathrm{CA}\right)$ at different engine-loads, determined as crank angles between MFB 5\% and MFB 90\%.

Both CD values (MFB 5-50\% and MFB 5-90\%) were the shortest for neat naphtha (5.2 and $20{ }^{\circ} \mathrm{CA}$ respectively) at the low load of 3.2 bar BMEP. Naphtha's low CN increased its ID but light fractions of neat naphtha burned rapidly, giving a short CD, especially MFB 5-50\%. RME's high oxygen content showed as rapid early burning-its MFB $5-50 \%$ CD of $5.2^{\circ} \mathrm{CA}$ was the same as naphtha's. The longest $\mathrm{CD}$ values at low load were measured for MGO $\left(6.8\right.$ and $\left.23^{\circ} \mathrm{CA}\right)$ due to its high viscosity that led to poor fuel/air mixing and hence longer combustion duration.

When engine-load was increased, the CD was first shortened (at 6.4 bar BMEP) and then prolonged (at 9.7 bar BMEP). Longer combustion duration is associated with an increase in fuel quantity for the higher engine-load [35]. At the medium load (6.4 bar BMEP), neat naphtha had the shortest CD figures (5.5 and $19^{\circ} \mathrm{CA}$ ) while $\mathrm{MGO}$ again had the longest $\mathrm{CD}\left(6.2\right.$ and $\left.21^{\circ} \mathrm{CA}\right)$. HVO showed almost as long as the total CD as MGO. Gabiña et al. [4] also measured longer (10-17\%) combustion durations for waste oil-based DLF than for diesel fuel oil (DFO) in a marine scale diesel engine. The combustion period started slightly earlier and ended slightly later with the DLF. The authors attributed this to DLF's higher $\mathrm{CN}$, which implied a shorter ID with a shorter premixed combustion phase, involving a lower pressure gradient, maximum combustion pressure and HRR.

At the high load (9.7 bar BMEP), the longest CD between MFB 5-50\% was measured for MGO and RME $\left(7.5^{\circ} \mathrm{CA}\right)$ and the shortest for kerosene, naphtha and naphtha20 $\left(7.1^{\circ} \mathrm{CA}\right)$. Unlike at lower loads, the shortest total $\mathrm{CD}$ was, however, observed for MGO $\left(22^{\circ} \mathrm{CA}\right)$. A higher in-cylinder temperature may have reduced the impact of MGO's higher viscosity. The longest total CD was measured for RME $\left(23^{\circ} \mathrm{CA}\right)$. Figure 4 clearly shows that the differences between the fuels' $\mathrm{CD}$ values decreased when the load increased. RME had relatively short $C D$ values at the low engine-loads, but was left behind when the load increased. Aldhaidhawi et al. [32] concluded in their review article that one of the disadvantages of using biodiesel is the longer combustion duration. RME's higher viscosity and density hinder mixture formation, leading to longer combustion duration and a lower rate of heat release.

\subsection{Cylinder Pressure}

At all loads, there were no major differences in maximum cylinder pressures between the studied fuels, as shown in Figure 5. The highest maximum cylinder pressure (105 bar at $14{ }^{\circ} \mathrm{CA}$ ATDC) was measured with MGO at the highest load. For comparison, the lowest maximum cylinder pressure at high engine-load was recorded with RME (101 bar at $15^{\circ} \mathrm{CA}$ ATDC), despite RME having the largest amount of injected fuel. Figure $2 \mathrm{a}-\mathrm{c}$ illustrate the cylinder-pressure traces. 


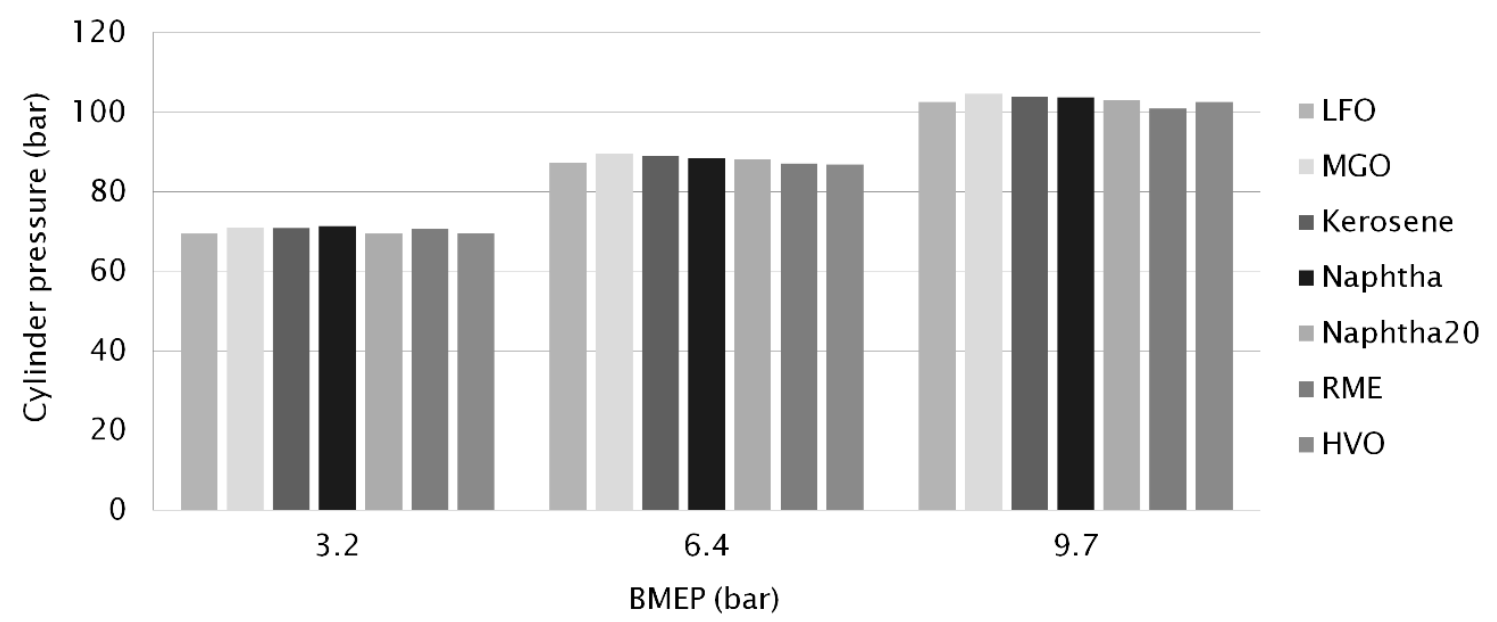

Figure 5. Maximum cylinder pressure versus engine load for different fuels.

At the low load (3.2 bar BMEP), rapid burning of neat naphtha produced the highest cylinder pressure. At the medium and high loads, the highest peaks of cylinder pressure were measured for MGO. Hissa et al. [17], showed a shorter ID and a higher maximum pressure increase for MGO than for LFO, naphtha or kerosene. Studies by Gabiña et al. [4] found that diesel-like fuel from WLO had almost the same combustion performance as pure diesel, and that the differences between the two fuels' performance decreased when engine size was increased.

CTO-based diesel (HVO) gave a very similar combustion performance as diesel. Even differences in combustion durations were minimal, at no more than $0.1{ }^{\circ} \mathrm{CA}$. Similar results were found by Heuser et al. [36] and Niemi et al. [5], where HVO from CTO was studied in passenger-car diesel engines and in a non-road diesel engine respectively.

\subsection{Gaseous Emissions and Smoke}

In the study by Ovaska et al. [24], the effects of alternative marine diesel fuels on the exhaust particle size distributions and gaseous emissions were observed. The results were provided from the same engine measurements as the current study. However, the research by Ovaska et al. (2019) does not include the results of neat naphtha and kerosene. In addition, the gaseous emission results are cycle-weighted brake specific emissions of $\mathrm{HC} \mathrm{NO}_{\mathbf{X}}, \mathrm{CO}$ according to the NRSC cycle (Table 6). The smoke number was also recorded.

Table 6. Cycle-weighted brake specific emissions of $\mathrm{HC}, \mathrm{NO}, \mathrm{CO}$ and smoke number ranges from lowest to highest within the non-road steady cycle (NRSC) with different fuels (Ovaska et al. [24]).

\begin{tabular}{ccccc}
\hline & HC & $\mathbf{N O}_{\mathbf{X}}$ & $\mathbf{C O}$ & Smoke \\
\cline { 2 - 5 } & $\mathbf{( g / \mathbf { k W h } )}$ & $\mathbf{( g / \mathbf { k W h } )}$ & $\mathbf{( g / k W h )}$ & $\mathbf{( F S N )}$ \\
\hline LFO & 0.24 & 9.3 & 0.33 & $0.014-0.038$ \\
MGO & 0.16 & 9.3 & 0.28 & $0.014-0.033$ \\
HVO & 0.20 & 8.9 & 0.32 & $0.013-0.031$ \\
RME & 0.12 & 10.8 & 0.30 & $0.005-0.015$ \\
Naphtha20 & 0.29 & - & 0.36 & $0.011-0.031$ \\
\hline
\end{tabular}

In general, $\mathrm{NO}_{X}$ emissions were the lowest with $\mathrm{HVO}$, while MGO and RME were favorable in terms of $\mathrm{CO}$ and $\mathrm{HC}$ emissions. The smoke numbers were minor with all fuels. More detailed results are provided in the article by Ovaska et al. [24]. 


\section{Conclusions}

The present study was carried out to evaluate the effects of the properties of alternative fuels in engine use, especially in-cylinder combustion, and to promote the development of fuel processes and standards to meet engine requirements. The results are useful to understand current trends in the fuel market and the impact that alternative fuels have in $\mathrm{CI}$ engine combustion.

Baseline fuel and six alternative liquid fuels were investigated in a high-speed diesel engine for non-road applications. The fuels were light fuel oil (LFO, baseline), recycled, waste lubricating oil (WLO), origin marine gas oil (MGO), kerosene, rapeseed methyl ester (RME), renewable diesel from crude tall oil (HVO), renewable wood-based naphtha and its blend with LFO (naphtha20). All measurements were performed under steady operation conditions without engine modifications. Multistage injections (pilot, main and post injections) were used throughout and the engine-speed of $1500 \mathrm{~min}^{-1}$ was maintained while conducting studies at three different engine-loads with brake mean effective pressures (BMEP) of 3.2 bar, 6.4 bar and 9.7 bar.

The investigated combustion parameters were very similar with all studied fuels. WLO-based MGO showed good combustion performance due to its high CN and short ID. The highest peak of cylinder pressure was measured for MGO, but the overall differences in cylinder pressures between fuels were minor. MGO's high CN and short ID meant the combustion started slightly earlier, but it also ended slightly later, giving a longer CD at the low and medium-load points. MGO's high viscosity may increase the combustion duration by hindering mixture formation. However, at the highest load, MGO's CD decreased relative to the other studied fuels. Similarly, MGO's combustion performance relative to the other fuels improved when the engine load was increased. However, high viscosity and its high sulphur-content are limiting factors for the use of MGO.

Naphtha's low CN increased the ID, but neat naphtha burned rapidly due to its low viscosity and density and the high volatility of its lighter compounds, which improved early combustion. Compared to LFO, naphtha's CD shortened as engine load decreased. Naphtha was level with MGO and kerosene in showing the highest cylinder pressures at all loads. Naphtha's HRR curve was slightly ahead of the other fuels, maybe because its low flash point and low viscosity promoted good air/fuel mixing. Neat naphtha's prolonged ID detracts from its combustion performance and limits its use as a drop-in fuel in a diesel engine. Moreover, neat naphtha needs other fuel (e.g. LFO) for starting and stopping the engine.

Naphtha20 was a blend of LFO and CTO-based naphtha-it showed overall combustion performance comparable to LFO's. That was also the case for CTO-based diesel, HVO. Both naphtha20 and HVO may be used in a diesel engine without any modifications.

Kerosene's light fractions not only increased its HRRs and cylinder pressures, but also decreased combustion duration compared to LFO. Nevertheless, kerosene's high sulphur-content limits its use in $\mathrm{CI}$ engines.

MGO with RME were favourable in terms of $\mathrm{CO}$ and $\mathrm{HC}$ emissions while the lowest $\mathrm{NO}_{\mathrm{X}}$ emissions were recorded with HVO. Smoke emission was negligible for all fuels. However, the emission results of neat naphtha or kerosene were not included.

All investigated alternative fuels can be used in a non-road engine without any modifications, except neat renewable naphtha. Despite the improved premixed combustion due to low viscosity and high-volatile, light compounds of naphtha, the ignition delay was prolonged and the engine load was limited. Moreover, naphtha had poor auto-ignition properties and required LFO for starting and stopping the engine. However, as a blend with LFO, renewable naphtha is suitable for CI engines if safety issues associated with its low flash point are solved.

Author Contributions: M.H., K.S. and T.O., investigation; M.H. and A.N., formal analysis; M.H. and T.O., writing-original draft preparation; S.N. and K.S., writing—review and editing; S.N., supervision

Funding: This project has received funding from the European Union's Horizon 2020 research and innovation program under grant agreement No 634135 (Hercules 2). 
Acknowledgments: The authors offer their appreciation toe Mrs. Sonja Heikkilä, Mr. Olav Nilsson and Ms. Nelli Vanhala for the assistance in the measurements.

Conflicts of Interest: The authors declare no conflicts of interest. The funders had no role in the design of the study; in the collection, analyses, or interpretation of data; in the writing of the manuscript, or in the decision to publish the results.

\section{Nomenclature}

$\begin{array}{ll}\text { ATDC } & \text { after top dead center } \\ \text { BMEP } & \text { brake mean effective pressure } \\ \text { BTDC } & \text { before top dead center } \\ \text { CA } & \text { crank angle } \\ \text { CD } & \text { combustion delay } \\ \text { CI } & \text { compression ignition } \\ \text { CN } & \text { cetane number } \\ \text { CRU } & \text { combustion research unit } \\ \text { CTO } & \text { crude tall oil } \\ \text { DLF } & \text { diesel-like fuel } \\ \text { ECA } & \text { Emission Control Area } \\ \text { EN } & \text { European Standard } \\ \text { EU } & \text { European Union } \\ \text { FAME } & \text { fatty acid methyl ester } \\ \text { HRR } & \text { heat release rate } \\ \text { HVO } & \text { hydrotreated vegetable oil } \\ \text { ICE } & \text { internal combustion engine } \\ \text { ID } & \text { ignition delay } \\ \text { LFO } & \text { light fuel oil } \\ \text { LHV } & \text { lower heating value } \\ \text { MFB } & \text { mass fraction burned } \\ \text { MGO } & \text { marine gas oil } \\ \text { NATO } & \text { North Atlantic Treaty Organization } \\ \text { RME } & \text { rapeseed methyl ester } \\ \text { UV } & \text { University of Vaasa } \\ \text { WLO } & \text { waste lubricant oils } \\ & \end{array}$

\section{References}

1. Intergovernmental Panel on Climate Change (IPCC). IPCC Press Release, 8 October 2018. Available online: https://www.ipcc.ch (accessed on 9 October 2018).

2. Alabbad, M.; Issayev, G.; Badra, J.; Voice, A.K.; Giri, B.R.; Djebbi, K.; Ahmed, A.; Sarathy, S.M.; Farooq, A. Autoignition of straight-run naphtha: A promising fuel for advanced compression ignition engines. Combust. Flame 2018, 189, 337-346. [CrossRef]

3. Hoppe, F.; Benedikt, H.; Thewes, M.; Kremer, F.; Pischinger, S.; Dahmen, M.; Hechinger, M.; Marquardt, W. Tailor-made fuels for future engine concepts. Int. J. Engine Res. 2016, 17, 16-27. [CrossRef]

4. Gabiña, G.; Martin, L.; Basurko, O.C.; Clemente, M.; Aldekoa, S.; Uriondo, Z. Performance of marine diesel engine in propulsion mode with a waste oil-based alternative fuel. Fuel 2019, 235, 259-268. [CrossRef]

5. Niemi, S.; Vauhkonen, V.; Mannonen, S.; Ovaska, T.; Nilsson, O.; Sirviö, K.; Heikkilä, S.; Kiijärvi, J. Effects of wood-based renewable diesel fuel blends on the performance and emissions of a non-road diesel engine. Fuel 2016, 186, 1-10. [CrossRef]

6. Sirviö, K. Issues of Various Alternative Fuel Blends for Off-Road, Marine and Power Plant Diesel Engines. Ph.D. Thesis, University of Vaasa, Vaasa, Finland, June 2018.

7. Heywood, J.B. Internal Combustion Engine Fundamentals, 2nd ed.; McGraw-Hill Education: New York, NY, USA, 2018; p. 1028. 
8. Pirjola, L.; Rönkkö, T.; Saukko, E.; Parviainen, H.; Malinen, A.; Alanen, J.; Saveljeff, H. Exhaust emissions of non-road mobile machine: Real-world and laboratory studies with diesel and HVO fuels. Fuel 2017, 202, 154-164. [CrossRef]

9. Sarvi, A.; Fogelholm, C.-J.; Zevenhoven, R. Emissions from large scale medium-speed diesel engines: 1. Influence of engine operation mode and turbocharger. Fuel Prosess. Technol. 2008, 89, 510-519. [CrossRef]

10. Bayindir, H.; Işik, M.Z.; Argunhan, Z.; Yücel, H.L.; Aydin, H. Combustion, performance and emissions of a diesel power generator fueled with biodiesel-kerosene and biodiesel-kerosene-diesel blends. Energy 2017, 123, 241-251. [CrossRef]

11. Naima, K.; Liazid, A. Waste oils alternative fuel for diesel engine: A review. J. Pet. Technol. Altern. Fuels 2013, 4, 30-43. [CrossRef]

12. Aramkitphotha, S.; Tanatavikorn, H.; Yenyuak, C.; Vitidsant, T. Low sulfur fuel oil from blends of microalgae pyrolysis oil and used lubricating oil: Properties and economic evaluation. Sustain. Energy Technol. Assess. 2019, 31, 339-346. [CrossRef]

13. Jiang, L.; Kronbak, J.; Christensen, L. The costs and benefits of sulphur reduction measures: Sulphur scrubbers versus marine gas oil. Transp. Res. Part D Transp. Environ. 2014, 28, 19-24. [CrossRef]

14. Wang, X.; Ni, P. Combustion and emission characteristics of diesel engine fueled with diesel-like fuel from waste lubrication oil. Energy Convers. Manag. 2017, 133, 275-283. [CrossRef]

15. Kang, D.; Kim, D.; Kalaskar, V.; Violi, A.; Boehman, A.L. Experimental characterization of jet fuels under engine relevant conditions-Part 1: Effect of chemical composition on autoignition of conventional and alternative jet fuels. Fuel 2019, 239, 1388-1404. [CrossRef]

16. Amara, A.B.; Dauphin, R.; Babiker, H.; Viollet, Y.; Chang, J.; Jeuland, N.; Amer, A. Revisiting diesel fuel formulation from Petroleum light and middle refinery streams based on optimized engine behaviour. Fuel 2016, 174, 63-75. [CrossRef]

17. Hissa, M.; Niemi, S.; Sirviö, K. Combustion property analyses with variable liquid marine fuels in combustion research unit. Agron. Res. 2018, 16, 1032-1045. [CrossRef]

18. Shahabuddin, M.; Liaquat, A.M.; Masjuki, H.H.; Kalam, M.A.; Mofijur, M. Ignition delay, combustion and emission characteristics of diesel engine fueled with biodiesel. Renew. Sustain. Energy Rev. 2013, 21, 623-632. [CrossRef]

19. World Wide Fuel Charter (WWFC5). Available online: http://www.oica.net/wp-content/uploads//WWFC52013-Final-single-page-correction2.pdf (accessed on 11 January 2019).

20. Brochure of BioVerno Naphtha, UPM. Available online: https://www.upmbiofuels.com/products/upmbioverno-naphtha/ (accessed on 9 January 2019).

21. Chang, J.; Kalghatgi, G.; Amer, A.; Adomeit, P.; Rohs, H.; Heuser, B. Vehicle Demonstration of Naphtha Fuel Achieving Both High Efficiency and Drivability with EURO6 Engine-Out $\mathrm{NO}_{X}$ Emission. SAE Int. J. Engines 2013, 6, 101-119. [CrossRef]

22. Bae, C.; Kim, J. Alternative fuels for internal combustion engines. Proc. Combust. Inst. 2017, 36, $3389-3413$. [CrossRef]

23. Subramanian, T.; Varuvel, E.; Ganapathy, S.; Vedharaj, S.; Vallinayagam, R. Role of fuel additives on reduction of $\mathrm{NO}_{X}$ emission from a diesel engine powered by camphor oil biofuel. Environ. Sci. Pollut. Res. 2018, 25, 15368-15377. [CrossRef]

24. Ovaska, T.; Niemi, S.; Sirviö, K.; Nilsson, O.; Portin, K.; Asplund, T. Effects of alternative marine diesel fuels on the exhaust particle size distributions of an off-road diesel engine. Appl. Therm. Eng. 2019, 150, 1168-1176. [CrossRef]

25. Fernandes, G.; Fuschetto, J.; Filipi, Z.; Assanis, A.; McKee, H. Impact of military JP-8 fuel on heavy-duty diesel engine performance and emissions. J. Automob. Eng. 2007, 221, 957-970. [CrossRef]

26. International Maritime Organization (IMO). Assessment of Fuel Oil Availability_Final Report; CE Delft: Delft, The Netherland, 2016; p. 183.

27. Finnish Standards Association (SFS). Automotive Fuels_Diesel_Requirements and Test Methods; SFS-EN 590:2013; Finnish Petroleum and Biofuels Association: Helsinki, Finland, 2013.

28. Arkoudeas, P.; Zannikos, F.; Lois, E. The tribological behavior of essential oils in low sulphur automotive diesel. Fuel 2008, 87, 3648-3654. [CrossRef] 
29. Hassaneen, A.; Munack, A.; Ruschel, Y.; Schroeder, O.; Krahl, J. Fuel economy and emission characteristics of Gas-to-Liqui (GTL) and Rapeseed Methyl Ester (RME) as alternative fuels for diesel engines. Fuel 2012, 97, 125-130. [CrossRef]

30. Tira, H.S.; Herreros, J.M.; Tsolakis, A.; Wyszynski, M.L. Characteristics of LPG-diesel dual fueled engine operated with rapeseed methyl ester and gas-to-liquid diesel fuels. Energy 2012, 47, 620-629. [CrossRef]

31. International Association of Classification Societies (IACS). Fuel Oil Safety Considerations Associated with the January 2020 0.50\% Sulphur Cap Requirement; Position Paper: London, UK, 2018; p. 2.

32. Aldhaidhawi, M.; Chiriac, R.; Badescu, V. Ignition delay, combustion and emission characteristics of Diesel engine fuelled with rapeseed biodiesel-A literature review. Renew. Sustain. Energy Rev. 2017, 73, 178-186. [CrossRef]

33. Niemi, S.A.; Murtonen, T.T.; Laurén, M.J.; Laiho, V.O.K. Exhaust Particulate Emissions of a Mustard Seed Oil Driven Tractor Engine. SAE Trans. J. Fuels Lubr. 2002, 111, 335-346. [CrossRef]

34. Vallinayagam, R.; An, Y.; Vedharaj, S.; Sim, J.; Chang, J.; Johansson, B. Naphtha vs. dieseline-The effect of fuel properties on combustion homogeneity in transition from CI combustion towards HCCI. Fuel 2018, 224, 451-460. [CrossRef]

35. Prakash, R.; Singh, R.K.; Murugan, S. Experimental studies on combustion, performance and emission characteristics of diesel engine using different biodiesel bio oil emulsions. J. Energy Inst. 2015, 88, 64-75. [CrossRef]

36. Heuser, B.; Vauhkonen, V.; Mannonen, S.; Rohs, H.; Kolbeck, A. Crude tall oil-based renewable diesel as a blending component in passenger car diesel engines. SAE Int. J. Fuels Lubr. 2013, 6, 817-825. [CrossRef]

(C) 2019 by the authors. Licensee MDPI, Basel, Switzerland. This article is an open access article distributed under the terms and conditions of the Creative Commons Attribution (CC BY) license (http://creativecommons.org/licenses/by/4.0/). 